\title{
MATHEMATICAL SIMULATION OF A SUPERSONIC COLLISIONLESS PLASMA FLOW AROUND A CONDUCTING CYLINDER
}

\author{
Institute of Technical Mechanics \\ of the National Academy of Sciences of Ukraine and the State Space Agency of Ukraine \\ 15 Leshko-Popel St., 49005,Dnipro,Ukraine; e-mail:vashuvalov@ukr.net
}

Simulating the interaction of a conducting body with a plasma flow is an important stage in the development of scientific and technological diagnostic devices and structural elements of advanced spacecraft and space systems. The aim of this paper is to substantiate the authors' algorithm for numerical simulation of the interaction of a conducting charged body with a rarefied plasma flow. The paper describes the key elements of the algorithm for solving the two-dimensional Vlasov-Poisson system by the example of a supersonic cross flow of a low-temperature nonisothermal rarefied plasma around a conducting cylinder. The algorithm allows the Vlasov equations to be solved by finitedifference splitting methods or the method of characteristics. When calculating the local equilibrium self-consistent electric field, the Vlasov-Poisson and Poisson-Boltzmann models were used for the electron component in the approximation of local equilibrium electrons and taking into account an electron sink on the body surface in the central field approximation. Criteria of applicability of the approximate Poisson-Boltzmann models in the vicinity of a body in a flow are formulated. The results obtained were verified both by test calculations for known model problems and by comparing the results of the solution of the same physical problems with the use of different mathematical models. The total current to a charged cylinder in a cross flow was calculated as a function of the electric potential, the ion velocity ratio, and the degree of plasma nonisothermality. The use of nested grids and a finite-difference splitting method for solving the Vlasov equations in the algorithm opens up opportunities for its further development to take into account particle collisions and to include charged particle sources and sinks in the analytical model. The results may be used in low-temperature rarefied plasma diagnostics and in the design of structural elements of spacecraft and space systems.

Keywords rarefied nonisothermal plasma flow, cross flow around a cylinder, Vlasov-Poisson system, splitting method, Poisson-Maxwell equation, model electron distribution, nested grids, calculation of the current to a cylinder.

1. Mott-Smith H., Langmuir I. The theory of collectors in gaseous discharges. Phys. Rev. 1926. V. 28. No. 5. Pp. 727-763.

2. Hoegy W. R., Wharton L. E., Current to a moving cylindrical electrostatic probe. Journal of Applied Physics. 1973. V. 44, No. 12. Pp. 5365-5371.

3. Chung P., Talbot L., Touryan K. Electric Probes in Stationary and Flowing Plasmas (in Russian). Moscow: Mir, 1978. $201 \mathrm{pp}$.

4. Godard R., Laframboise J. Total current to cylindrical collectors in collision less plasma flow. Planetary Space Science. 1983. V. 31. No. 3. p. 275-283.

5. $X u G$. Z. The interaction of a moving spacecraft with the ionosphere: Current collection and wake structure : Ph.D. dissertation. York University, 1992. 258 pp.

6. Choiniere E. Theory and experimental evaluation of a consistent steady-state kinetic model for twodimensional conductive structures in ionospheric plasmas with application to bare electrodynamic tethers in space : Ph.D. dissertation. University of Michigan, 2004. 288 pp.

7. Alpert L. A., Gurevich A. V., Pitaevsky L. G. Satellites in a Rarefied Plasma (in Russian). Moscow: Nauka, 1964. $382 \mathrm{pp}$.

8. Lazuchenkov D. N., Lazuchenkov N. M. Simulation of interactions between rarified plasma flow and faired charged conducting cylinder near conducting surface (in Russian). Teh. Meh. 2014. No. 2. Pp. 63-72.

9. Koshmarov Yu. ., Ryzhev Yu. A. Applied Mechanics of a Rarefied Gas (in Russian). Moscow: Mashinostroyeniye, 1977. $184 \mathrm{pp}$.

10. Lazuchenkov $D$. N. Calculation of an electron-repulsing self-consistent electric field near a cylinder in a rarefied plasma flow (in Russian). Teh. Meh. 2012. No. 4. Pp. 27-35.

11 Sigov Yu. S. Numerical Methods in Plasma Kinetic Theory (in Russian). Moscow: MFTI, 1984. 94 pp.

12. Titarev V. A., Shakhov E. M. Numerical calculation of supersonic cross flow of a rarefied gas about a cold plate (in Russian). Mekhanika Zhidkosti i Gaza. 2005. No. 5. Pp. 140 - 154.

13. Latramboise J. G. Theory of Spherical and Cylindrical Langmuir Probes in a Collisionless Maxwellian Plasma at Rest. Report, No. 100. Univ. of Toronto, Institute of Aerospace Studies. 1966. 210 pp.

14. Samarsky A. A., Nikolaev E. S. Grid Equation Solution Methods (in Russian). Moscow: Nauka, 1978. 592 pp.

15. Lazuchenkov D. M., Lazuchenkov M. M. Interpretation of probe measurements in a collisionless plasma flow. Teh. Meh. 2018. No. 1. Pp. 107-120.

16. Birdsall C., Langdon . Plasma Physics via Computer Simulation (in Russian). Moscow: Energoatomizdat, 1989. $452 \mathrm{pp}$.

17. Kiel R. ., Gey F. C., Gustafson W. A. Electric potential fields of an ionosphere satellite (in Russian). RTK. 1968. No. 4. Pp. 139-145. 
18. Alekseev B. V., Kotelnikov V. A. Probe Method for Plasma Diagnostics. Moscow: Energoatomizdat, 1988. 240 pp.

Received on February 12, 2019,

in final form on March 4, 2019 